\title{
Genetically Determined Amerindian Ancestry Correlates With Increased Frequency of Risk Alleles for Systemic Lupus Erythematosus
}

\author{
Elena Sanchez, ${ }^{1}$ Ryan D. Webb, ${ }^{2}$ Astrid Rasmussen, ${ }^{1}$ Jennifer A. Kelly, ${ }^{1}$ Laura Riba, ${ }^{3}$ \\ Kenneth M. Kaufman, ${ }^{4}$ Ignacio Garcia-de la Torre, ${ }^{5}$ Jose F. Moctezuma, ${ }^{6}$ \\ Marco A. Maradiaga-Ceceña, ${ }^{7}$ Mario H. Cardiel-Rios, ${ }^{8}$ Eduardo Acevedo, ${ }^{9}$ \\ Mariano Cucho-Venegas, ${ }^{9}$ Mercedes A. Garcia, ${ }^{10}$ Susana Gamron, ${ }^{11}$ Bernardo A. Pons-Estel, ${ }^{12}$ \\ Carlos Vasconcelos, ${ }^{13}$ Javier Martin, ${ }^{14}$ Teresa Tusié-Luna, ${ }^{3}$ John B. Harley, ${ }^{15}$ \\ Bruce Richardson, ${ }^{16}$ Amr H. Sawalha, ${ }^{4}$ and Marta E. Alarcón-Riquelme ${ }^{17}$
}

Objective. To assess whether genetically determined Amerindian ancestry predicts increased presence of risk alleles of known susceptibility genes for systemic lupus erythematosus (SLE).

Methods. Single-nucleotide polymorphisms (SNPs) within 16 confirmed genetic susceptibility loci

Supported by NIH grants R03-AI-076729 from the National Institute of Allergy and Infectious Diseases, P20-RR-020143, and P30-AR-053483, and by the Lupus Foundation of America, the University of Oklahoma Health Sciences Center, the Oklahoma City VAMC, and the Oklahoma Medical Research Foundation. Dr. Harley's work was supported by NIH grants AR-062277, AR-042460, AI-024717, AI-083194, and RR-020143. Dr. Alarcón-Riquelme's work was supported by the Swedish International Development Agency, the Swedish Research Council for Medicine, the Instituto de Salud Carlos III, and NIH grants AR-058621 from the National Institute of Arthritis and Musculoskeletal and Skin Diseases (American Recovery and Reinvestment Act), CA-141700, and AI-083194.

${ }^{1}$ Elena Sanchez, PhD, Astrid Rasmussen, MD, PhD, Jennifer A. Kelly, MPH: Oklahoma Medical Research Foundation, Oklahoma City; ${ }^{2}$ Ryan D. Webb, MPH: University of Oklahoma Health Sciences Center, Oklahoma City; ${ }^{3}$ Laura Riba, MIBB, Teresa Tusié-Luna, MD, $\mathrm{PhD}$ : Instituto de Investigaciones Biomédicas de la Universidad Nacional Autónoma de México, and Instituto Nacional de Ciencias Médicas y Nutrición Salvador Zubirán, Mexico City, Mexico; ${ }^{4} \mathrm{Ken}-$ neth M. Kaufman, PhD, Amr H. Sawalha, MD: Oklahoma Medical Research Foundation, University of Oklahoma Health Sciences Center, and VAMC, Oklahoma City; ${ }^{5}$ Ignacio Garcia-de la Torre, MD: Hospital General de Occidente, Zapopan, Mexico; ${ }^{6}$ Jose F. Moctezuma, MD: Hospital General de México, Mexico City, Mexico; ${ }^{7}$ Marco A. Maradiaga-Ceceña, MD: Hospital General de Culiacán, Culiacan, Mexico; ${ }^{8}$ Mario H. Cardiel-Rios, MD, MSc: Hospital General Dr. Miguel Silva, Morelia, Mexico; ${ }^{9}$ Eduardo Acevedo, MD, Mariano Cucho-Venegas, MD: Hospital Nacional Guillermo Almenara Irigoyen, Lima, Peru; ${ }^{10}$ Mercedes A. Garcia, MD: Hospital Interzonal General de Agudos "General San Martín," La Plata, Argentina; ${ }^{11}$ Susana Gamron, MD: Hospital Nacional de Clínicas, Universidad Nacional de Córdoba, Cordoba, Argentina; ${ }^{12}$ Bernardo A. Pons-Estel, MD: Sanatorio Parque, Rosario, Argentina; ${ }^{13}$ Carlos Vasconcelos, for SLE were genotyped in a set of 804 Mestizo lupus patients and 667 Mestizo healthy controls. In addition, 347 admixture informative markers were genotyped. Individual ancestry proportions were determined using STRUCTURE. Association analysis was performed using PLINK, and correlation between ancestry and the presence of risk alleles was analyzed using linear regression.

Results. A meta-analysis of the genetic association of the 16 SNPs across populations showed that TNFSF4, STAT4, ITGAM, and IRF5 were associated with lupus in a Hispanic Mestizo cohort enriched for European and Amerindian ancestry. In addition, 2 SNPs

MD, PhD: Hospital Santo Antonio, Unidade Multidisciplinar em Investigação Biomédica/Instituto de Ciências Biomédicas de Abel Salazar, Porto, Portugal; ${ }^{14}$ Javier Martin, MD, PhD: Instituto de Biomedicina y Parasitología López-Neyra, Consejo Superior de Investigaciones Científicas, Granada, Spain; ${ }^{15} \mathrm{John}$ B. Harley, MD, PhD: Cincinnati Children's Hospital Medical Center, Cincinnati, Ohio; ${ }^{16}$ Bruce Richardson, MD, PhD: University of Michigan and VAMC, Ann Arbor; ${ }^{17}$ Marta E. Alarcón-Riquelme, MD, PhD: PfizerUniversidad de Granada-Junta de Andalucía, Granada, Spain and Oklahoma Medical Research Foundation, Oklahoma City. this work.

Drs. Sawalha and Alarcón-Riquelme contributed equally to

Dr. Vasconcelos has received consulting fees, speaking fees, and/or honoraria from Merck, Sharp, and Dohme and Roche (less than $\$ 10,000$ each). Dr. Harley has received consulting fees, speaking fees, and/or honoraria from Biorad Labs, Immunovision, and IVAX Diagnostics (more than $\$ 10,000$ each) and owns stock in IVAX Diagnostics.

Address correspondence and reprint requests to Marta E. Alarcón-Riquelme, MD, PhD, Oklahoma Medical Research Foundation, 825 NE 13th Street, MS \#24, Oklahoma City, OK 73104. E-mail: alarconm@omrf.org.

Submitted for publication April 20, 2010; accepted in revised form September 9, 2010. 
within the major histocompatibility complex region, previously shown to be associated in a genome-wide association study in Europeans, were also associated in Mestizos. Using linear regression, we predicted an average increase of $\mathbf{2 . 3 4}$ risk alleles when comparing an SLE patient with $100 \%$ Amerindian ancestry versus an SLE patient with $0 \%$ Amerindian ancestry $(P<$ 0.0001). SLE patients with $43 \%$ more Amerindian ancestry were predicted to carry 1 additional risk allele.

Conclusion. Our results demonstrate that Amerindian ancestry is associated with an increased number of risk alleles for SLE.

Differences in the prevalence and severity of systemic lupus erythematosus (SLE) between various ethnicities are well documented. In particular, individuals of self-reported Hispanic (or Mestizo), Asian, or African ancestry in the US and Europe have been shown to have an earlier age at onset of SLE, a higher frequency of severe SLE-associated renal disease, and a higher frequency of relapses of SLE than individuals of European ancestry (1-8). While socioeconomic factors play a role in the increased morbidity and mortality among Hispanic individuals, the question of whether the presence of genetically defined ancestry correlates with an increased frequency of risk alleles for lupus has never been analyzed. We have previously shown that an increased proportion of Amerindian genome increases the risk for SLE (9), and this observation was confirmed in another study (10). Further, a strong genetic association between IRF5 and SLE in Mexican individuals, combined with an increased frequency of homozygosity for the risk haplotype, has been reported (11).

In the present work we analyzed 804 Mestizo individuals with lupus for genetic association with polymorphisms within 16 confirmed SLE susceptibility loci (12-31) and investigated whether the frequency of risk alleles correlates with a higher proportion of genetically determined Amerindian ancestry as defined using a set of admixture informative markers. We found that, in Mestizo SLE patients, Amerindian ancestry increases the odds of having more lupus risk alleles as compared with European ancestry.

\section{PATIENTS AND METHODS}

Cases and controls. A total of 804 patients with SLE and 667 healthy controls were studied. Three hundred seventythree of the SLE cases and 272 of the controls were from the Lupus Family Registry and Repository at Oklahoma Medical Research Foundation (OMRF) (http://lupus.omrf.org). The great majority of these individuals are of Mexican ancestry and were born in and/or living in the US. Two hundred forty-two SLE cases and 240 controls were from a multicenter collaboration in Argentina (the Argentine Lupus Collaboration [Appendix A]); these subjects have been previously reported and were used in analyses of genetic associations for STAT4 (12), IRF5 (13), BANK1 (19), and TNFSF4 (20). The remaining subjects are individuals reported here for the first time, from the Latin American Collaboration on Lupus, which is enrolling and studying SLE patients from Latin America on an ongoing basis. These subjects comprise 101 SLE cases and 64 controls from throughout Mexico (specifically, from the cities of Guadalajara, Morelia, Culiacan, and Mexico City) and 88 cases and 91 controls from Lima, Peru. All cases fulfilled the American College of Rheumatology classification criteria for SLE (32).

Genotyping. Genotyping was performed using the Illumina Custom Bead system on an iSCAN instrument. Genotypes for the following single-nucleotide polymorphisms (SNPs) within 16 confirmed susceptibility genes for SLE were used: rs2476601 (PTPN22), rs1801274 (FCGR2A), rs2205960 (TNFSF4), rs7574865 (STAT4), rs231775 (CTLA4), rs11568821 (PDCD1), rs6445975 (PXK), rs10516487 (BANK1), rs907715 (IL21), rs3131379 (MSH5, within the class III major histocompatibility complex [MHC] region), rs1270942 (CFB, within the class III MHC region), rs2070197 (IRF5), rs13277113 (C8ORF13-BLK region), rs1800450 (MBL2), rs4963128 (KIAA1542), and rs1143679 (ITGAM) (12-31).

In addition, 347 admixture informative markers were used to genotype all individuals (33-35) (see Supplementary Table 1, available in the online version of this article at http://onlinelibrary.wiley.com/journal/10.1002/(ISSN)15290131). We selected a panel of admixture informative markers that had large frequency differences between European populations and Amerindian populations. In addition, the intermarker distance between 2 adjacent admixture informative markers was at least $1 \mathrm{Mb}$, to ensure that the admixture informative markers were not in linkage disequilibrium in the parental populations.

Population structure determination. Population structure was analyzed with STRUCTURE, version 2.3.1 (36), which implements a model-based clustering method for inferring population substructure using admixture informative markers. We set most of the parameters to their default values as advised in the user's manual. Specifically, we chose the admixture model and the option of correlated allele frequencies between populations, as suggested by Falush et al (36). The range of possible populations we tested was $K 3-5$, as described (35). The best-fitting $K$ was 4 , as a mixture of 4 populations: African, European, Asian, and Amerindian.

We selected genotypes from European, Amerindian, Asian, and African individuals in the HapMap version 3 data set (37) as potential ancestral populations. Subjects were excluded if they showed $>10 \%$ African or Asian ancestry, in order to enrich for 2 ancestral populations, European and Amerindian. Among the samples, 45 individuals were excluded from further analyses.

Principal components analysis. To account for confounding population substructure or admixture in the studied population, we used principal components analysis (38-41) as implemented in HelixTree, using genotype data from the 347 admixture informative markers. The first 3 principal compo- 
Table 1. Average ancestry proportions of the population sets studied

\begin{tabular}{lcccr}
\hline \multicolumn{1}{c}{ Population } & No. of individuals & Amerindian & South European & North European \\
\hline Yoruba (YRI; HapMap version 3) & 167 & 0.001 & 0.000 & 0.001 \\
European (CEU; HapMap version 3) & 165 & 0.003 & 0.003 & 0.998 \\
Spain & 1,062 & 0.013 & 0.868 & 0.000 \\
Portugal & 386 & 0.008 & 0.863 & 0.114 \\
Mexico & 165 & 0.529 & 0.353 & 0.126 \\
Peru & 179 & 0.726 & 0.096 \\
Argentina & 482 & 0.247 & 0.645 & 0.052 \\
OMRF Hispanic* & 645 & 0.307 & 0.454 & 0.022 \\
\end{tabular}

* OMRF $=$ Oklahoma Medical Research Foundation.

nents explained $71.7 \%$ of the variance among the first 10 principal components and had eigenvalues of 42.1,21.3, and 8.3. The eigenvalues for principal components $4-10$ showed a plateau, suggesting that the first 3 principal components accounted for most of the populations' substructure in this analysis. All individuals who were not clustering with the main Amerindian cluster (more than 4 SD from cluster centroids) were excluded from subsequent analysis. Using this method, we identified 23 outlier individuals ( 15 healthy controls and 8 SLE patients).

Statistical genetic analysis. The genetic association analysis was performed using PLINK, version 1.0.7 (42). First, quality control filters were applied to remove SNPs with differential rates of missing data between cases and controls $(P<0.05)$, significant deviation from Hardy-Weinberg equilibrium in controls $(P<0.001)$, or a minor allele frequency of $<1 \%$. Allele frequencies of the remaining SNPs (16 of 16) were tested by chi-square test for significant association within each study population. The meta-analysis of all of the populations was conducted using standard methods based on the Cochran-Mantel-Haenszel test (43). The Breslow-Day test (44) was performed for all SNPs, to assess heterogeneity of the odds ratios in different populations. The pooled odds ratio was calculated according to a fixed-effects model (MantelHaenszel meta-analysis) for SNPs with homogeneity between populations, as well as a random-effects model (DerSimonianLaird) when heterogeneity was present, using StatsDirect software, version 2.4.6. Alternatively, we also derived principal components on a population-specific basis using HelixTree, version 7.2.3, and applied an adjustment for the first 5 principal components.

Regression analysis. We used linear regression to model the relationship between the proportion Amerindian ancestry and the number of SLE risk alleles. Our initial model included proportion Amerindian ancestry, sex, and the interaction between sex and Amerindian ancestry as predictor variables for the number of SLE risk alleles. There was no evidence of interaction, so we refit the model with the 2 remaining predictor variables. Since we were interested in the association between the number of risk alleles and the proportion Amerindian ancestry, we removed sex from the model as neither predictor variable was significant while both were fit. Our final model included the proportion Amerindian ancestry as a predictor of the number of SLE risk alleles. All linear modeling assumptions were assessed and met.

\section{RESULTS}

Population structure analyses showed the following mean proportions of Amerindian ancestry for each of the sets included (Table 1): Amerindian ancestry was $30.7 \%$ among OMRF Hispanics, 24.7\% among Argentines (consistent with what we had described previously) (45), 52.9\% among Mexicans, and $72.6 \%$ among Peruvians. OMRF Hispanics differed from the Latin American subjects from Mexico, Peru, and Argentina in that the former group had a higher proportion of North European ancestry, suggesting that some of the samples may include second- or third-generation Mexican Americans where inclusion of the European American genetic pool, mainly of North European ancestry, has occurred. On the other hand, the Latin American groups had a substantial proportion of South European ancestry (Table 1), as expected by the known history of these populations.

For individual ancestry proportions, there were no differences between cases and controls in the 4 clusters. In addition, we did not observe any differences after comparing the clusters with and without prior populations.

We first determined the genetic association with each of the 16 SLE SNPs, for the overall group of Hispanic cases and the overall group of Hispanic controls. Association was observed for TNFSF4, STAT4, IRF5, MSH5, CFB, and ITGAM, and a trend toward association was observed for PDCD1 (Table 2). The SNPs for C8orf13-BLK, BANK1, and PXK showed a significant degree of heterogeneity across the different country sets $(P<0.0001, P=0.023$, and $P=0.001$, respectively), and this could have contributed to the fact that the final meta-analysis did not show a genetic association for these variants. This is particularly true for the C8orf13-BLK SNP, but it might not explain the 
Table 2. Meta-analysis of the genetic association of 16 risk gene polymorphisms in Hispanic subjects*

\begin{tabular}{|c|c|c|c|c|c|c|c|}
\hline Gene/SNP & $\begin{array}{c}\text { GG, } \\
\text { no. }(\%)\end{array}$ & $\begin{array}{c}\text { AG, } \\
\text { no. }(\%)\end{array}$ & $\begin{array}{c}\text { AA, } \\
\text { no. }(\%)\end{array}$ & $\begin{array}{c}\text { Allele G, } \\
\text { no. }(\%)\end{array}$ & $\begin{array}{c}\text { Allele A, } \\
\text { no. }(\%)\end{array}$ & OR $(95 \% \mathrm{CI})$ & $P$ \\
\hline \multicolumn{8}{|l|}{ PTPN22/rs2476601 } \\
\hline SLE patients $(\mathrm{n}=794)$ & $712(89.7)$ & $81(10.2)$ & $1(0.1)$ & $1,595(94.8)$ & $83(5.2)$ & \multirow[t]{2}{*}{$1.233(0.866-1.754)$} & \multirow[t]{2}{*}{0.2832} \\
\hline Controls $(n=648)$ & $596(91.8)$ & $49(7.6)$ & $3(0.6)$ & $1,241(95.6)$ & $55(4.4)$ & & \\
\hline \multicolumn{8}{|l|}{ FCGR2A/rs1801274 } \\
\hline SLE patients $(\mathrm{n}=767)$ & $184(25.8)$ & $385(50.2)$ & 198 (24) & $781(51)$ & $753(49)$ & \multirow[t]{2}{*}{$0.885(0.762-1.027)$} & \multirow[t]{2}{*}{0.1182} \\
\hline Controls $(n=640)$ & $178(22.7)$ & $317(49.5)$ & $145(27.8)$ & $607(47.4)$ & $673(52.6)$ & & \\
\hline \multicolumn{8}{|l|}{ TNFSF4/rs2205960 } \\
\hline SLE patients $(\mathrm{n}=794)$ & $310(39)$ & $381(48)$ & $103(13)$ & $1,001(63)$ & $587(37)$ & \multirow[t]{2}{*}{$1.488(1.269-1.745)$} & \multirow[t]{2}{*}{$1.65 \times 10^{-6}$} \\
\hline Controls $(n=649)$ & $329(50.7)$ & $265(40.8)$ & $55(8.5)$ & $923(71)$ & $375(28.9)$ & & \\
\hline \multicolumn{8}{|l|}{ STAT4/rs7574865 } \\
\hline SLE patients $(\mathrm{n}=727)$ & $268(36.9)$ & $350(48.1)$ & $109(15)$ & $886(61)$ & $568(39)$ & \multirow[t]{2}{*}{$1.41(1.2-1.659)$} & \multirow[t]{2}{*}{$5.81 \times 10^{-5}$} \\
\hline Controls $(n=595)$ & $255(42.9)$ & $276(46.4)$ & $64(10.8)$ & $786(66.1)$ & $404(33.9)$ & & \\
\hline \multicolumn{8}{|l|}{ CTLA4/rs231775 } \\
\hline SLE patients $(\mathrm{n}=783)$ & $294(37.5)$ & $364(46.5)$ & $125(16)$ & $952(60.8)$ & $614(39.2)$ & \multirow[t]{2}{*}{$0.976(0.838-1.137)$} & \multirow[t]{2}{*}{0.7882} \\
\hline Controls $(n=640)$ & $246(38.4)$ & $300(46.9)$ & $94(14.7)$ & $792(62)$ & $488(38)$ & & \\
\hline \multicolumn{8}{|l|}{$P D C D 1 / \mathrm{rs} 11568821$} \\
\hline SLE patients $(\mathrm{n}=778)$ & $671(86.2)$ & $102(13.1)$ & $5(0.6)$ & $1,444(92.8)$ & $112(7.2)$ & \multirow[t]{2}{*}{$0.758(0.576-0.997)$} & \multirow[t]{2}{*}{0.0571} \\
\hline Controls $(\mathrm{n}=636)$ & $529(83.2)$ & 99 (15.6) & $8(1.3)$ & $1,157(91)$ & $115(9)$ & & \\
\hline \multicolumn{8}{|l|}{$P X K / \mathrm{rs} 6445975$} \\
\hline SLE patients $(\mathrm{n}=785)$ & $332(42.3)$ & $350(44.6)$ & $103(13.1)$ & $1,114(64.6)$ & $556(35.4)$ & \multirow[t]{2}{*}{$1.077(0.8-1.45)$} & \multirow[t]{2}{*}{0.622} \\
\hline Controls $(\mathrm{n}=647)$ & $290(44.8)$ & $280(43.3)$ & 77 (11.9) & $860(66.5)$ & $434(33.5)$ & & \\
\hline$B A N K 1 / \mathrm{rs} 10516487$ & & & & & & & \\
\hline SLE patients $(\mathrm{n}=753)$ & $536(71.2)$ & $190(25.2)$ & $27(3.6)$ & $1,262(83.8)$ & $244(16.2)$ & $0.711(0.425-1.189)$ & 0.194 \\
\hline Controls $(\mathrm{n}=612)$ & $402(65.7)$ & $179(29.2)$ & $31(5.1)$ & $983(80.3)$ & $241(19.7)$ & & \\
\hline IL21/rs907715 & & & & & & & \\
\hline SLE patients $(\mathrm{n}=781)$ & $353(45.2)$ & $345(44.2)$ & $83(10.6)$ & $1,051(67.3)$ & $511(32.7)$ & $1.107(0.942-1.299)$ & 0.2298 \\
\hline Controls $(n=635)$ & $307(48.3)$ & $267(42)$ & 16 (19.6) & $881(69.4)$ & $389(30.6)$ & & \\
\hline MSH5/rs3131379 & & & & & & & \\
\hline SLE patients $(\mathrm{n}=796)$ & $692(86.9)$ & $102(12.8)$ & $2(0.3)$ & $1,486(93.3)$ & $106(6.7)$ & $1.773(1.255-2.505)$ & 0.0013 \\
\hline Controls $(\mathrm{n}=651)$ & $602(92.5)$ & $48(7.4)$ & $1(0.2)$ & $1,252(96.2)$ & $50(3.8)$ & & \\
\hline$C F B /$ rs1270942 & & & & & & & \\
\hline SLE patients $(\mathrm{n}=796)$ & $698(87.7)$ & $96(12.1)$ & $2(0.3)$ & $1,492(93.7)$ & $100(6.3)$ & $1.881(1.311-2.698)$ & 0.0007 \\
\hline Controls $(\mathrm{n}=652)$ & $608(93.3)$ & $43(6.6)$ & $1(0.2)$ & $1,259(96.5)$ & $45(3.5)$ & & \\
\hline IRF5/rs2070197 & & & & & & & \\
\hline SLE patients $(\mathrm{n}=768)$ & $507(66)$ & $233(30.3)$ & $28(3.6)$ & $1,247(81.2)$ & $289(18.8)$ & $2.058(1.632-2.595)$ & $1.65 \times 10^{-9}$ \\
\hline Controls $(\mathrm{n}=536)$ & $421(78.5)$ & $104(19.4)$ & $11(2.1)$ & $946(88.2)$ & $126(11.8)$ & & \\
\hline C8orf-BLK/rs13277113 & & & & & & & \\
\hline SLE patients $(\mathrm{n}=753)$ & $232(31)$ & $362(48.3)$ & $155(20.7)$ & $826(55.1)$ & $672(44.9)$ & $1.228(0.771-1.955)$ & 0.3869 \\
\hline Controls $(\mathrm{n}=611)$ & $252(41.2)$ & $262(42.9)$ & $97(15.9)$ & 766 (62.7) & $456(37.3)$ & & \\
\hline$M B L 2 / \mathrm{rs} 1800450$ & & & & & & & \\
\hline SLE patients $(\mathrm{n}=793)$ & $510(64.3)$ & $253(31.9)$ & $30(3.8)$ & $1,273(80.3)$ & $313(19.7)$ & $1.058(0.878-1.276)$ & 0.5831 \\
\hline Controls $(\mathrm{n}=648)$ & $424(65.4)$ & $195(30.1)$ & $29(4.5)$ & $1,043(80.5)$ & $253(19.5)$ & & \\
\hline KIAA1542/rs4963128 & & & & & & & \\
\hline SLE patients $(\mathrm{n}=762)$ & $375(49.2)$ & $311(40.8)$ & $76(10)$ & $1,061(69.6)$ & $463(30.4)$ & $0.983(0.835-1.157)$ & 0.8761 \\
\hline Controls $(\mathrm{n}=632)$ & $358(51.7)$ & $280(40.4)$ & $55(7.9)$ & $996(72)$ & $390(28)$ & & \\
\hline ITGAM/rs1143679 & & & & & & & \\
\hline SLE patients $(\mathrm{n}=795)$ & $538(67.7)$ & $234(29.4)$ & $23(2.9)$ & $1,310(82.4)$ & $280(17.6)$ & $2.232(1.767-2.818)$ & $6.22 \times 10^{-11}$ \\
\hline Controls $(n=650)$ & $541(83.2)$ & $102(15.7)$ & $7(1.1)$ & $1,184(91.1)$ & $116(8.9)$ & & \\
\hline
\end{tabular}

* SNP = single-nucleotide polymorphism; OR = odds ratio; 95\% CI = 95\% confidence interval; SLE = systemic lupus erythematosus.

results for $B A N K 1$ and $P X K$, which could relate to insufficient power for detection of the genetic association.

We have previously shown that Amerindian ancestry increases the risk for lupus (9), and this was later confirmed (10). Therefore, we investigated whether the proportion of Amerindian ancestry in an individual had any effect on the number of risk alleles. Linear regression (Figure 1) showed that, on average, one could predict an increase of 2.34 SLE risk alleles in a subject with $100 \%$ Amerindian ancestry as compared with a subject with $0 \%$ of such ancestry $(P<0.0001)$, and an individual with $43 \%$ more Amerindian ancestry would have, on average, 1 additional risk allele. 


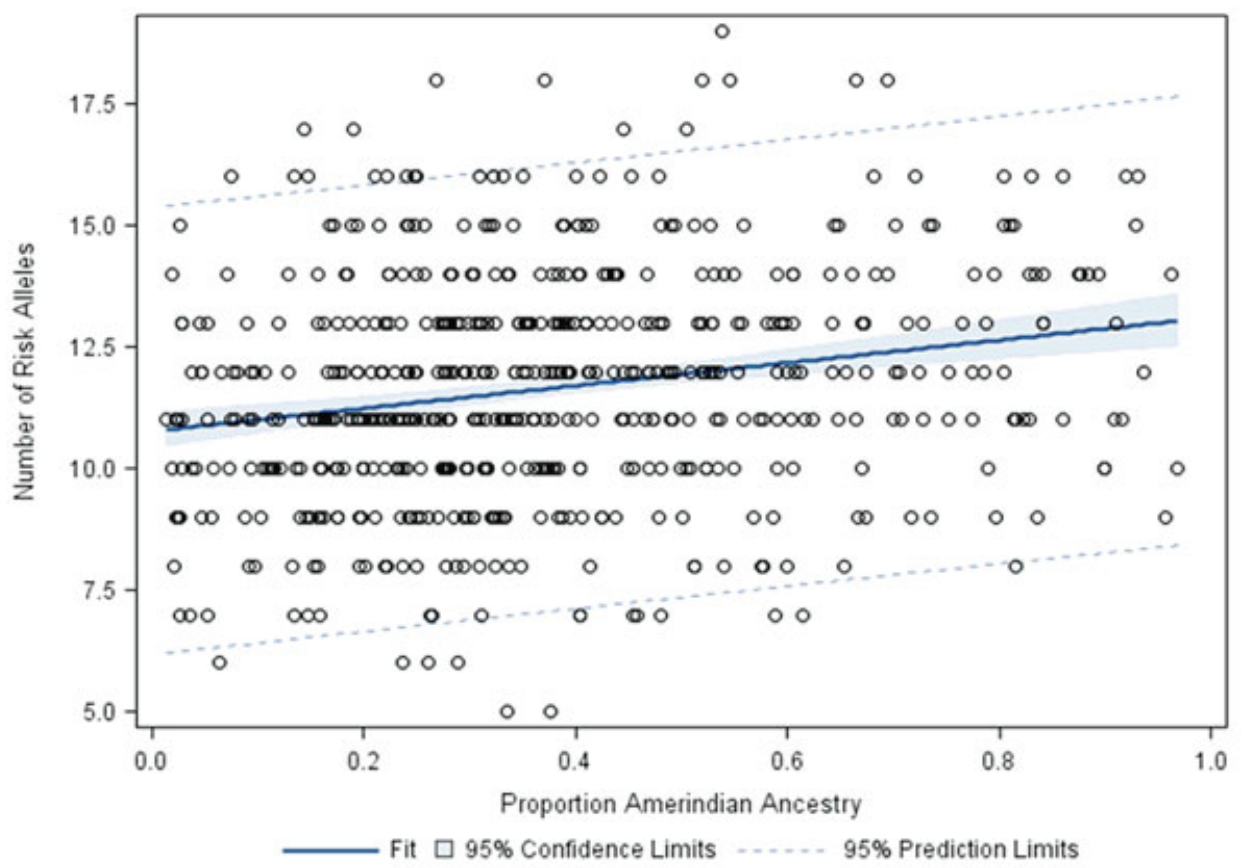

Figure 1. Scatterplot of the input data, overlaid with the fitted regression line, $95 \%$ confidence limits, and 95\% prediction limits. The $95 \%$ confidence limits in the plot are pointwise limits that cover the mean number of risk alleles for a particular proportion of Amerindian ancestry with probability of 0.95 . The $95 \%$ prediction limits illustrate the pointwise limits, with probability of 0.95 , for a future measurement of risk alleles in relation to a given proportion of Amerindian ancestry.

\section{DISCUSSION}

It has been consistently shown that patients of Mestizo (Hispanic) descent have more severe clinical lupus disease, severe SLE-related renal disease, and earlier age at onset. Mestizos are a very heterogeneous group of individuals with different cultural backgrounds but in general a common mother tongue, Spanish. The complexity of the Mestizo population does not allow for appropriate genetics studies unless such complexity is taken into consideration (1). With the aim of investigating whether genes identified as being related to lupus in Europeans also play a role in the disease in Mestizos, we selected a group from Latin American countries with an enrichment of Amerindian and European ancestries based on population history, and a group of Hispanic subjects from the US, primarily originating from Mexico.

In general, the populations of Mexico, Peru, and Argentina have a lower proportion of African ancestry and are primarily of European and Amerindian ancestry. Our collection also includes samples from southern Europe (Spain and Portugal) as a reference, so we were able to discern between North and South Europeans. In this regard, Hispanic subjects from the OMRF showed a high proportion of North European ancestry, in accordance with recent inclusion of a European American gene pool.

Testing of the 16 SNPs representing risk variants of lupus susceptibility genes described in Europeans confirmed the genetic associations previously found for IRF5, STAT4, TNFSF4, ITGAM, and to a lesser degree, the 2 SNPs within the MHC region and PDCD1. Interestingly, the 2 SNPs used here for the MHC were the same ones included in the genome-wide association study, and in that study the highest genetic association in Europeans was detected with those genes (16). In the present study, the genetic associations of the non-MHC variants were stronger than for the MHC, suggesting two possibilities: either the MHC effect originates from the European admixture on the Amerindian background and it is "diluted," and/or other Amerindian genes play a very important role in disease susceptibility in Hispanics and in some way substitute for the strong effect of the MHC in Europeans. However, these 2 SNPs in the MHC region do not tag MHC haplotypes and cannot be seen as representing the main effect on the MHC region in this population. For this, dense coverage of the region 
would be required. Such studies are under way; we are at present performing a genome-wide association study in Hispanic Mestizo individuals to address this question.

With regard to the remaining genetic association it is important to point out that this replication is not completely independent: the samples from the Argentine subjects have been used previously in our work on BANK1, IRF5, TNFSF4, and STAT4 $(12,13,19,20)$. Our previous work (9) showed an increased frequency of Amerindian genome in patients with SLE in the same set of Argentine subjects, whereas in the present study we observed a very similar average proportion of Amerindian genome between cases and controls; however, we also have included new samples in the present study. The previous work used a completely different, and smaller, set of admixture informative markers. At this point, we are unable to explain the reason for the discrepancy.

Because the sets of Mexican and Peruvian samples used for the first time in this study were each relatively small, the associations were not discernible at the individual cohort level. In the Peruvian sample there was weak association with FCGR2A $(P=0.02), I R F 5(P$ $=0.004)$, and ITGAM $(P=0.01)$, while association with BANK1 $(P=0.0002)$ and ITGAM $(P=0.001)$ was shown in the Mexican set. Most of the contribution to the genetic associations observed in the meta-analysis was provided by the Argentine and the OMRF Hispanic cohorts.

PDCD1 warrants further discussion. We identified $P D C D 1$ as a susceptibility gene for lupus after linkage analysis in Icelandic and Swedish multiplex families, and we described a polymorphism in intron 4 associated with SLE, with replication in European American, Swedish, and Mexican cases (31). A second independent study replicated this genetic association in Mexican pediatric SLE patients (46), and a correlation between surface levels of $P D C D 1$ protein (programmed death 1 [PD-1]) in CD4+CD25+ T cells and the associated variants (known as PD-1.3) was recently described (47). In the present study, the association was observed only in the Argentine SLE cases and controls $(P=$ 0.013 ), a set not previously analyzed for this polymorphism. Important, and possibly affecting our results, is the fact that the Argentine set had the highest proportion of European ancestry; this may also be the reason the association was detectable in that set. Finally, no association with CTLA4, IL21, MBL2, or KIAA1542 was observed, while $B L K$ showed, as mentioned above, extensive heterogeneity. The negative results for $B L K$ in the meta-analysis should be viewed with caution.
What is the significance of the increased risk, among individuals with Amerindian genome, of carrying risk alleles of lupus susceptibility genes identified in Europeans? First, it is possible that in Hispanics/ Mestizos, the "European" risk alleles interact with genes that are important on the Amerindian background. This is somewhat reminiscent of what happens in New Zealand mouse strains, where the New Zealand white background interacts with genes found in the New Zealand black background, leading to a strong and florid lupus-like disease in the resultant $F_{1}$ strain $(48,49)$. In that scenario Mestizo individuals from Latin America would, to some degree, behave as a sort of genetic $\mathrm{F}_{1}$, where unknown genetic interactions might occur, leading to an increased risk of developing severe SLE in the admixed population. On the other hand, our results might also be explained by an enrichment of European risk alleles due to positive selection.

From the data presented here we can suggest that the admixture may in part be responsible for the increased susceptibility to SLE, and that the Amerindian background genome contributes to this increased risk. Studies to identify genes of Amerindian origin that contribute to the increased risk of the disease are clearly warranted.

\section{ACKNOWLEDGMENTS}

The authors would like to thank Drs. Carl Langefeld and Jasmin Divers for the selection of admixture informative markers for the LLAS2 project, and Maria Luisa OrdoñezSanchez, Rosario Rodriguez-Guillen, and Farideh Movafagh for technical assistance.

\section{AUTHOR CONTRIBUTIONS}

All authors were involved in drafting the article or revising it critically for important intellectual content, and all authors approved the final version to be published. Dr. Alarcón-Riquelme had full access to all of the data in the study and takes responsibility for the integrity of the data and the accuracy of the data analysis.

Study conception and design. Sanchez, Riba, Kaufman, Tusié-Luna, Sawalha, Alarcón-Riquelme.

Acquisition of data. Sanchez, Kelly, Riba, Kaufman, Garcia-de la Torre, Moctezuma, Maradiaga-Ceceña, Cardiel-Rios, Acevedo, Cucho-Venegas, Garcia, Gamron, Pons-Estel, Vasconcelos, TusiéLuna, Harley, Alarcón-Riquelme.

Analysis and interpretation of data. Sanchez, Webb, Rasmussen, Kaufman, Moctezuma, Cucho-Venegas, Martin, Richardson, Sawalha, Alarcón-Riquelme.

\section{REFERENCES}

1. Pons-Estel BA, Catoggio LJ, Cardiel MH, Soriano ER, Gentiletti $\mathrm{S}$, Villa AR, et al. The GLADEL multinational Latin American prospective inception cohort of 1,214 patients with systemic lupus 
erythematosus: ethnic and disease heterogeneity among "Hispanics." Medicine (Baltimore) 2004;83:1-17.

2. Alarcon GS, Bastian HM, Beasley TM, Roseman JM, Tan FK, Fessler BJ, et al. Systemic lupus erythematosus in a multi-ethnic cohort (LUMINA): contributions of admixture and socioeconomic status to renal involvement [published erratum appears in Lupus 2006;15:386]. Lupus 2006;15:26-31.

3. Alarcon GS, McGwin G Jr, Bartolucci AA, Roseman J, Lisse J, Fessler BJ, et al, for the LUMINA Study Group Systemic lupus erythematosus in three ethnic groups. IX. Differences in damage accrual. Arthritis Rheum 2001;44:2797-806.

4. Alarcon GS, McGwin G Jr, Bastian HM, Roseman J, Lisse J, Fessler BJ, et al, for the LUMINA Study Group. Systemic lupus erythematosus in three ethnic groups. VIII. Predictors of early mortality in the LUMINA cohort [published erratum appears in Arthritis Rheum 2001;45:306]. LUMINA Study Group. Arthritis Rheum 2001;45:191-202.

5. Calvo-Alen J, Reveille JD, Rodriguez-Valverde V, McGwin G Jr, Baethge BA, Friedman AW, et al. Clinical, immunogenetic and outcome features of Hispanic systemic lupus erythematosus patients of different ethnic ancestry. Lupus 2003;12:377-85.

6. Ghaussy NO, Sibbitt W Jr, Bankhurst AD, Qualls CR. The effect of race on disease activity in systemic lupus erythematosus. J Rheumatol 2004;31:915-9.

7. Odutola J, Ward MM. Ethnic and socioeconomic disparities in health among patients with rheumatic disease. Curr Opin Rheumatol 2005;17:147-52.

8. Vila LM, Alarcon GS, McGwin G Jr, Friedman AW, Baethge BA, Bastian HM, et al. Early clinical manifestations, disease activity and damage of systemic lupus erythematosus among two distinct US Hispanic subpopulations. Rheumatology (Oxford) 2004;43: $358-63$.

9. Seldin MF, Qi L, Scherbarth HR, Tian C, Ransom M, Silva G, et al. Amerindian ancestry in Argentina is associated with increased risk for systemic lupus erythematosus. Genes Immun 2008;9: 389-93.

10. Molineros JE, Kim-Howard X, Deshmukh H, Jacob CO, Harley JB, Nath SK. Admixture in Hispanic Americans: its impact on ITGAM association and implications for admixture mapping in SLE. Genes Immun 2009;10:539-45.

11. Reddy MV, Velazquez-Cruz R, Baca V, Lima G, Granados J, Orozco L, et al. Genetic association of IRF5 with SLE in Mexicans: higher frequency of the risk haplotype and its homozygosity than Europeans. Hum Genet 2007;121:721-7.

12. Abelson AK, Delgado-Vega AM, Kozyrev SV, Sanchez E, Velazquez-Cruz R, Eriksson N, et al. STAT4 associates with systemic lupus erythematosus through two independent effects that correlate with gene expression and act additively with IRF5 to increase risk. Ann Rheum Dis 2009;68:1746-53.

13. Graham RR, Kozyrev SV, Baechler EC, Reddy MV, Plenge RM, Bauer JW, et al. A common haplotype of interferon regulatory factor 5 (IRF5) regulates splicing and expression and is associated with increased risk of systemic lupus erythematosus. Nat Genet 2006;38:550-5.

14. Sigurdsson S, Nordmark G, Goring HH, Lindroos K, Wiman AC, Sturfelt $G$, et al. Polymorphisms in the tyrosine kinase 2 and interferon regulatory factor 5 genes are associated with systemic lupus erythematosus. Am J Hum Genet 2005;76:528-37.

15. Remmers EF, Plenge RM, Lee AT, Graham RR, Hom G, Behrens TW, et al. STAT4 and the risk of rheumatoid arthritis and systemic lupus erythematosus. N Engl J Med 2007;357:977-86.

16. Harley JB, Alarcon-Riquelme ME, Criswell LA, Jacob CO, Kimberly RP, Moser KL, et al. Genome-wide association scan in women with systemic lupus erythematosus identifies susceptibility variants in ITGAM, PXK, KIAA1542 and other loci. Nat Genet 2008;40:204-10.

17. Hom G, Graham RR, Modrek B, Taylor KE, Ortmann W, Garnier
S, et al. Association of systemic lupus erythematosus with C8orf13BLK and ITGAM-ITGAX. N Engl J Med 2008;358:900-9.

18. Nath SK, Han S, Kim-Howard X, Kelly JA, Viswanathan P, Gilkeson GS, et al. A nonsynonymous functional variant in integrin- $\alpha(\mathrm{M})$ (encoded by ITGAM) is associated with systemic lupus erythematosus. Nat Genet 2008;40:152-4.

19. Kozyrev SV, Abelson AK, Wojcik J, Zaghlool A, Linga Reddy MV, Sanchez E, et al. Functional variants in the B-cell gene BANK1 are associated with systemic lupus erythematosus [published erratum appears in Nat Genet 2008;40:484]. Nat Genet 2008;40:211-6.

20. Delgado-Vega AM, Abelson AK, Sanchez E, Witte T, D'Alfonso $\mathrm{S}$, Galeazzi M, et al. Replication of the TNFSF4 (OX40L) promoter region association with systemic lupus erythematosus. Genes Immun 2009;10:248-53.

21. Graham DS, Graham RR, Manku H, Wong AK, Whittaker JC, Gaffney PM, et al. Polymorphism at the TNF superfamily gene TNFSF4 confers susceptibility to systemic lupus erythematosus. Nat Genet 2008;40:83-9.

22. Sawalha AH, Kaufman KM, Kelly JA, Adler AJ, Aberle T, Kilpatrick J, et al. Genetic association of IL-21 polymorphisms with systemic lupus erythematosus. Ann Rheum Dis 2008:67: 458-61.

23. Bottini N, Vang T, Cucca F, Mustelin T. Role of PTPN22 in type 1 diabetes and other autoimmune diseases. Semin Immunol 2006;18:207-13.

24. Brand O, Gough S, Heward J. HLA, CTLA-4 and PTPN22 : the shared genetic master-key to autoimmunity? Expert Rev Mol Med 2005;7:1-15.

25. Aguilar F, Torres B, Sanchez-Roman J, Nunez-Roldan A, Gonzalez-Escribano MF. CTLA4 polymorphism in Spanish patients with systemic lupus erythematosus. Hum Immunol 2003;64:936-40.

26. Garred P, Madsen HO, Halberg P, Petersen J, Kronborg G, Svejgaard A, et al. Mannose-binding lectin polymorphisms and susceptibility to infection in systemic lupus erythematosus. Arthritis Rheum 1999;42:2145-52.

27. Davies EJ, Snowden N, Hillarby MC, Carthy D, Grennan DM, Thomson W, et al. Mannose-binding protein gene polymorphism in systemic lupus erythematosus. Arthritis Rheum 1995;38:110-4.

28. Salmon JE, Millard S, Schachter LA, Arnett FC, Ginzler EM, Gourley MF, et al. Fc $\gamma$ RIIA alleles are heritable risk factors for lupus nephritis in African Americans. J Clin Invest 1996;97: 1348-54.

29. Zuniga R, Ng S, Peterson MG, Reveille JD, Baethge BA, Alarcon GS, et al. Low-binding alleles of $\mathrm{Fc} \gamma$ receptor types IIA and IIIA are inherited independently and are associated with systemic lupus erythematosus in Hispanic patients. Arthritis Rheum 2001;44: $361-7$.

30. Edberg JC, Langefeld CD, Wu J, Moser KL, Kaufman KM, Kelly $\mathrm{J}$, et al. Genetic linkage and association of $\mathrm{Fc} \gamma$ receptor IIIA (CD16A) on chromosome 1q23 with human systemic lupus erythematosus. Arthritis Rheum 2002;46:2132-40.

31. Prokunina L, Castillejo-Lopez C, Oberg F, Gunnarsson I, Berg L, Magnusson $\mathrm{V}$, et al. A regulatory polymorphism in PDCD1 is associated with susceptibility to systemic lupus erythematosus in humans. Nat Genet 2002;32:666-9.

32. Hochberg MC, for the Diagnostic and Therapeutic Criteria Committee of the American College of Rheumatology. Updating the American College of Rheumatology revised criteria for the classification of systemic lupus erythematosus [letter]. Arthritis Rheum 1997;40:1725.

33. Yang N, Li H, Criswell LA, Gregersen PK, Alarcon-Riquelme ME, Kittles R, et al. Examination of ancestry and ethnic affiliation using highly informative diallelic DNA markers: application to diverse and admixed populations and implications for clinical epidemiology and forensic medicine. Hum Genet 2005:1-11.

34. Tian C, Hinds DA, Shigeta R, Adler SG, Lee A, Pahl MV, et al. 
A genomewide single-nucleotide-polymorphism panel for Mexican American admixture mapping. Am J Hum Genet 2007;80: 1014-23.

35. Kosoy R, Nassir R, Tian C, White PA, Butler LM, Silva G, et al. Ancestry informative marker sets for determining continental origin and admixture proportions in common populations in America. Hum Mutat 2009;30:69-78.

36. Falush D, Stephens M, Pritchard JK. Inference of population structure using multilocus genotype data: linked loci and correlated allele frequencies. Genetics 2003;164:1567-87.

37. International HapMap Consortium. The International HapMap Project. Nature 2003;426:789-96.

38. Patterson N, Price AL, Reich D. Population structure and eigenanalysis. PLoS Genet 2006;2:e190.

39. Price AL, Patterson NJ, Plenge RM, Weinblatt ME, Shadick NA, Reich D. Principal components analysis corrects for stratification in genome-wide association studies. Nat Genet 2006;38:904-9.

40. Epstein MP, Allen AS, Satten GA. A simple and improved correction for population stratification in case-control studies. Am J Hum Genet 2007;80:921-30.

41. Reich D, Price AL, Patterson N. Principal component analysis of genetic data. Nat Genet 2008;40:491-2.

42. Purcell S, Neale B, Todd-Brown K, Thomas L, Ferreira MA, Bender D, et al. PLINK: a tool set for whole-genome association and population-based linkage analyses. Am J Hum Genet 2007; 81:559-75.

43. Guedj M, Wojcik J, Della-Chiesa E, Nuel G, Forner K. A fast, unbiased and exact allelic test for case-control association studies. Hum Hered 2006;61:210-21.

44. Breslow NE, Day NE, Halvorsen KT, Prentice RL, Sabai C. Estimation of multiple relative risk functions in matched casecontrol studies. Am J Epidemiol 1978;108:299-307.

45. Seldin MF, Tian C, Shigeta R, Scherbarth HR, Silva G, Belmont JW, et al. Argentine population genetic structure: large variance in Amerindian contribution. Am J Phys Anthropol 2007;132:455-62.

46. Velazquez-Cruz R, Orozco L, Espinosa-Rosales F, Carreno-Manjarrez R, Solis-Vallejo E, Lopez-Lara ND, et al. Association of PDCD1 polymorphisms with childhood-onset systemic lupus erythematosus. Eur J Hum Genet 2007;15:336-41.

47. Kristjansdottir H, Steinsson K, Gunnarsson I, Grondal G, Erlendsson K, Alarcon-Riquelme ME. Lower expression levels of the programmed death 1 receptor on $\mathrm{CD} 4+\mathrm{CD} 25+\mathrm{T}$ cells and correlation with the PD-1.3A genotype in patients with systemic lupus erythematosus. Arthritis Rheum 2010;62:1702-11.
48. Drake CG, Babcock SK, Palmer E, Kotzin BL. Genetic analysis of the NZB contribution to lupus-like autoimmune disease in $($ NZB $\times$ NZW)F1 mice. Proc Natl Acad Sci U S A 1994;91: 4062-6.

49. Drake CG, Rozzo SJ, Vyse TJ, Palmer E, Kotzin BL. Genetic contributions to lupus-like disease in $(\mathrm{NZB} \times \mathrm{NZW}) \mathrm{F} 1$ mice. Immunol Rev 1995;144:51-74.

\section{APPENDIX A: MEMBERS OF THE ARGENTINE LUPUS COLLABORATION}

Members of the Argentine Lupus Collaboration are as follows: Bernardo A. Pons-Estel, MD (Coordinator of the Argentine Lupus Collaboration) (Sanatorio Parque, Rosario); Jorge A. Lopez, MD, Estela L. Motta, MD, Hugo R. Scherbarth, MD (Hospital Interzonal General de Agudos "Dr. Oscar Alende," Mar del Plata); Sandra Buliubasich, MD, Susana Gamron, MD, Emilia Menso, MD (Hospital Nacional de Clínicas, Universidad Nacional de Córdoba, Cordoba); Alberto Allievi, MD, Jose L. Presas, MD (Hospital General de Agudos "Dr. Juán A. Fernandez," Buenos Aires); Guillermo A. Tate, MD (Organización Médica de Investigación, Buenos Aires); Mariela Bearzotti, PhD, Simon A. Palatnik, MD (Universidad Nacional de Rosario y Hospital Provincial del Centenario, Rosario); Alejandro Alvarellos, MD, Ana Bertoli, MD, Francisco Caeiro, MD (Hospital Privado, Centro Médico de Córdoba, Cordoba); Carlos Louteiro, MD, Sergio Paira, MD, Susana Roverano, MD (Hospital "José M. Cullen," Santa Fe); Estela Bertero, PhD, Cesar E. Graf, MD (Hospital San Martín, Parana); Griselda Buchanan, PhD, Cesar Caprarulo, MD (Hospital Felipe Heras, Concordia, Entre Rios); Sebastian Grimaudo, PhD, Carolina Guillerón, MD, Jorge Manni, MD (Instituto de Investigaciones Médicas "Alfredo Lanari," Buenos Aires); Luis J. Catoggio, Carlos D. Santos, MD, Enrique R. Soriano, MD (Hospital Italiano de Buenos Aires y Fundación "Dr. Pedro M. Catoggio" para el Progreso de la Reumatología, Buenos Aires); Sandra M. Navarro, MD, Cristina Prigione, MD, Fernando A. Ramos, MD (Hospital Provincial de Rosario, Rosario); Guillermo A. Berbotto, MD, Marisa Jorfen, MD, Elisa J. Romero, PhD (Hospital Escuela Eva Perón, Granadero Baigorria); Mercedes A. Garcia, MD, Ana I. Marcos, MD, Juan C. Marcos, MD (Hospital Interzonal General de Agudos "General San Martín," La Plata); Alicia Eimon, MD, Carlos E. Perandones, MD (Centro de Educación Médica e Investigaciones Clínicas, Buenos Aires); Cristina G. Battagliotti, MD (Hospital de Niños Dr. Orlando Alassia, Santa Fe). 